\title{
Camões no anti-humanismo
}

\section{Camoens in the anti-humanism}

\author{
Rafael Santana Gomes \\ Professor Adjunto de Literatura Portuguesa na UFRJ
}

Resumo: Este artigo propõe uma leitura da poesia camoniana a partir da perspectiva do Humanismo e da defesa dos direitos humanos. De inegável dicção filosófica, o discurso épico de Camões apresenta-se como um gesto de resistência contra a reificação dos valores humanitários propalados no seu tempo.

Palavras-chave: Camões; Humanismo; Resistência.

Abstract: This paper aims to read Camoens' poetry from the perspective of humanism and that of the human rights defense. With undeniable philosophical diction, Camoens' epic discourse presents itself as a gesture of resistance against the reification of the humanitarian values spread in his time.

Keywords: Camoens; Humanism; Resistance.

Em memória do professor José Carlos Barcellos, o maior humanista que já conheci!

Sou um ser humano, nada do humano considero alheio a mim (Terêncio). 
Tá não mais que dois anos, li pela primeira vez um artigo 1 de Achille Mbembe cujo título me deixou verdadeiramente intrigado: "The age of humanism is ending" (A era do humanismo está terminando). Curioso frente a esta assertiva tão apocalipticamente anunciada, mergulhei no texto do filósofo camaronês com imenso espanto, constatando aí uma série de temas já por mim algumas vezes intuídos mas nunca satisfatoriamente articulados num pensamento tão bem costurado. Composto pelo sufixo grego ismo (doutrina, crença, postura) e pelo adjetivo latino humanus (humano), o humanismo é etimologicamente a doutrina do humano na sua relação com o $h u-$ mus, com a terra. Daí que, embora historicamente atrelado aos séculos XIV, XV e XVI europeus, ainda possamos falar, sem risco de equívoco, no desenvolvimento de uma cultura humanista desde a Antiguidade Clássica, que fizera do homem o cânone mesmo da ciência, da ética, da política, da arte.

No seu monumental Dicionário de filosofia Nicola Abbagnano atenta em pelo menos quatro desdobramentos possíveis para termo humanista, que ganharia em ser lido a partir do 1) reconhecimento da totalidade do homem; 2) reconhecimento da historicidade do homem; 3) reconhecimento do valor humano das letras clássicas; 4) reconhecimento da naturalidade do homem. Ora, diante do exposto, não será difícil inferir que estamos a viver atualmente numa era a que poderíamos chamar anti-humanista, tempo no qual, diz Achille Mbembe, a "noção humanística e iluminista do sujeito racional capaz de deliberação e escolha [é] substituída pela do consumidor conscientemente deliberante e eleitor" (2017, p.2). Diluída pois a noção do sujeito racional, uma atmosfera nebulosa, violenta e fundamentalista se nos apresenta sob a bandeira cruel de um discurso perigosamente fascista e, não poucas vezes, teocrático, cioso de extirpar toda e qualquer rubrica da diferença. A revivificação contemporânea de políticas ultraconservadoras ao redor do mundo, bem como a onda crescente e avassaladora dos regimes de ultradireita, seria um sintoma claríssimo do desprezo pela cultura e pelos ideais humanísticos, que apostam seja no diálogo, seja no conhecimento científico-filosófico (de si, do outro e do mundo) como possíveis vias de crescimento. 
Não bastasse este cenário mundial nada amigável, o Brasil do presente vive quiçá um dos períodos mais negros da sua História, em que um fundamentalismo neopentecostal de ordem midiática adentra a esfera da política a todo vapor, levando-nos a vivenciar uma espécie de simbólica "Idade das Trevas", assentada num conceito unívoco de sagrado, de hierarquia, de religião, de tradição e de família. Nova "Idade das Trevas" que contudo não abdica dos valores mercantilistas; ao contrário, os ratifica em tudo aquilo que o capitalismo tem mais perverso! Na afã da defesa unilateral dos seus princípios conservadores, a extrema-direita põe sob ataque frontal os direitos humanos e uma nova eugenia - não mais a da raça pura mas a dos humanos direitos - é acintosamente proposta. Perseguem-se os direitos humanos e, por conseguinte, as ciências humanas. Destarte não é de surpreender o anúncio do governo, no dia 26 de abril de 2019, a decretar o fim das faculdades de Filosofia e Sociologia, com o objetivo de "focar em áreas que gerem retorno imediato".

Confesso que sempre me questionei a respeito da necessidade do retorno econômico imediato em se tratando da função da universidade. E foi imensamente comovido que li o artigo intitulado "Qual o limite?", da autoria de Jane Tutikian, vice-reitora da Universidade Federal do Rio Grande do Sul, publicado a 30 de abril de 2019 no jornal Hora do Povo. Em meio às reflexões ali estabelecidas, pergunta-se a escritora: "Desde quando o papel da universidade é gerar retorno imediato?”. E prossegue: "Universidade é mais, muito mais do que isso: é patrimônio da sociedade, é onde se produz conhecimento, e as Humanidades têm um papel fundamental nesse contexto". Ao que conclui em tom de questionamento: Pode-se imaginar uma vida sem literatura, sem artes, sem história, sem pensamento? Uma vida sem cultura!" (2019. p.20). Também não consigo imaginar uma vida sem cultura nem deixar de contemplar a universidade como um espaço de formação cultural. E é aí que diviso um paradoxo que, há pouco mais de duas décadas, todos nós, acadêmicos, jovens ou não, vimos enfrentando: o tempo da cultua versus o tempo da produção. Ora, sabemos que o tempo da cultura não é de nenhum modo equivalente ao tempo da produção e que por isso 
mesmo as exigências que atualmente se imputam à academia quer no âmbito docente, quer no discente não correspondem a outro fenômeno senão ao da adequação mercadológica ao modelo neoliberal, fascinado que é pelas estatísticas, pelos rankings, pelas tabelas classificatórias ${ }^{32}$. Daí que sejamos avaliados, tanto professores quanto alunos, pela quantidade de produtos que disponibilizamos para a sociedade, como se o conhecimento que formulamos correspondesse exatamente a uma mercadoria a ser consumida e sujeitada às leis da oferta e da procura. Quando a universidade, cujo grande modelo foi idealizado precisamente no tempo do Humanismo, passa a pensar-se menos em termos qualitativos e mais em quantitativos, menos em quesitos de formação cultural e mais em formação de produtos, ela está justamente a trair a herança legada pelos filósofos humanistas. Noutras palavras, quando a academia se curva à lógica tecnocrática da produção acelerada, é chegada a hora de reconfigurá-la para que não venha a cair também ela na era do anti-humanismo! Não estamos longe, uma vez mais, das reflexões de Achille Mbembe, para quem:

Nesta nova paisagem, o conhecimento será definido como conhecimento para o mercado. O próprio mercado será re-imaginado como o mecanismo principal para a validação da verdade. Como os mercados estão se transformando cada vez mais em estruturas e tecnologias algorítmicas, o único conhecimento útil será algorítmico. Em vez de pessoas com corpo, história e carne, inferências estatísticas serão tudo o que conta. As estatísticas e outros dados importantes serão derivados principalmente da computação. Como resultado da confusão de conhecimento, tecnologia e mercados, o desprezo se estenderá a qualquer pessoa que não tiver nada para vender. $(2017$, p.3)

Histórias de pessoas com corpo e carne importam e é preciso salientar que o nosso tempo não é - nem foi - o único $32 \quad$ A este fenômeno chama Marilena Chauí universidade operacional: "Definida e estruturada por normas e padrões inteiramente alheios ao conhecimento e à formação intelectual, está pulverizada em microorganizações que ocupam seus docentes e curvam seus estudantes a exigências exteriores ao trabalho intelectual. A heteronomia da universidade autônoma é visível a olho nu: o aumento insano de horas/aula, a diminuição do tempo para mestrados e doutorados, a avaliação pela quantidade de publicações, colóquios e congressos, a multiplicação de comissões e relatórios etc." (Chauí, 2003, p.7) 
a experimentar a ameaça da perda dos valores humanitários e, em sentido mais específico, da cultura humanista. Aliás, o próprio Humanismo enquanto tal teve de enfrentar este problema seríssimo! Basta lembrar que o antropocentrismo, que legitimara todo o movimento, nascera precisamente da crise do sistema medieval e da contestação do seu pensamento teocêntrico. Recuperando o argumento filosófico de Protágoras, o homem do Humanismo passava a ser a medida de todas as coisas, o que não significava - em linguagem nietzschiana - a morte de Deus mas um profundo abalar de uma estrutura absolutamente hermética, fechada em si mesma, para a qual o mundo não seria senão o reflexo do querer divino, e não é por acaso que, no entendimento do homem medieval, a História, as artes plásticas, a literatura, enfim, os âmbitos da ação humana em geral eram todos eles metafisicamente mediados. Na cultura humanista, muito pelo contrário, o homem, observando a lição dos clássicos mas sempre atento ao seu presente material e histórico, faz do seu corpo e da sua mente o reduto mesmo da sabedoria. Verdadeiro filósofo da condição humana, o artista humanista, que recuperava da Antiguidade Clássica os mais altos ideais da cultura e da civilização com vista ao alcance desta mesma grandeza no seu tempo, assistira ele próprio à reificação dos conceitos que propagava, uma vez que o mercantilismo, que possibilitara a passagem do mundo medieval ao moderno, trazia como saldo negativo a substituição do lugar especialíssimo que se queria conferir à arte e ao pensamento pelo culto infame e desmedido ao dinheiro.

É como forma de resistência, ou melhor, é para resistir aos desvios ideológicos da Itália de então e sobretudo à perda da sua própria condição humana que Dante, no crepúsculo da Idade Média, perdido numa alegórica "Selva Escura", decide iniciar a sua larga jornada épica; é refletindo e escrevendo sobre a sua condição existencial no enfrentamento com o mundo que Petrarca se torna um dos primeiros pensadores modernos do Ocidente; e é como reação a um mundo desconcertado que Camões estabelece uma série de especulações poético-filosóficas sobre um tempo e um espaço ensurdecidos à poesia, entregues que estavam ao "gosto da cobiça" (X, 145). É especifica- 
mente sobre estas especulações filosóficas da poesia camoniana que quero pensar!

Em O Tejo é um rio controverso, Jorge Fernandes da Silveira insiste por mais de uma vez na ideia de que "a recepção é o problema central d'Os Lusíadas no seu tempo e através dos tempos" (2008, p.56). Concordo com o professor e, recebendo o poema a partir de toda uma problemática do meu tempo, ou ainda, lendo Camões como um poeta contemporâneo que quando fala do e para o seu tempo não deixa de falar também do e para o meu/nosso tempo, como tão bem sinalizou Helder Macedo (2013), evoco novamente as palavras do ilustre crítico brasileiro nos seus brilhantes argumentos contra as interpretações um tanto engessadas de António José Saraiva:

[...] ao invés de se afastar, Camões aproxima-se do pensamento dos humanistas, que criticavam a redução da história a feitos de armas. 'Por este lado vazio', espécie de labirinto, se bem o entendo, que leva o poeta, no último Canto, a invocar o silêncio, consciente de que é a própria morte que sentencia, vitimado pela 'contradição central do poema', aqui entendida, porém, não como morte por causa natural em decorrência duma 'ideologia oca', mas sim como a consciência dilacerada de quem não foi capaz de criar o leitor hábil, inteligente, discreto e curioso, o leitor novo; novo entre o valor medieval, reservado e religioso, de amor à leitura, e o livro visto como objeto mundano de experiência na modernidade. Tempo de experiências extraordinárias. Tantas e tamanhas que 'o peito ilustre lusitano' seria visto de fato como resultado de uma abstração de e na linguagem, isto é, um objeto real novo para o conhecimento, que o transforma em nova imagem no e pelo canto, ou seja, em cada gesto de escrita e de leitura. O Portugal de Camões, porém, entre a Idade Média e o Renascimento, não deixa de ser o camponês velho nem chega a ser o novo marinheiro. Noutras palavras: não alcança a idade da razão por meio do amor ao Livro. (2008, pp.25-26)

Eduardo Lourenço sinaliza, de longa data, que em se tratando da literatura e da cultura portuguesas escapar a Camões será sempre uma impossibilidade. Fala-se muitas vezes com Camões, certas vezes contra Camões, mas nunca sem Camões. "É impossível comemorar Os Lusíadas inocentemente" (2010, p.155), diz o renomado ensaísta em sintagma já largamente repetido e, no entanto, a tautologia aqui também se 
faz necessária. Porque, se no seu tempo e através dos tempos o poema camoniano foi recebido e lido tão diversamente a ponto de justificar, no uso político que dele foi feito, desde a ascensão de um projeto liberal até ao estabelecimento de um regime ditatorial, é porque a sua linguagem foi capaz de trapacear não apenas com a língua mas também com os seus leitores. Camões é o poeta vivo que me interessa mais ${ }^{33}$ e leio no seu Os Lusíadas um texto subversivo, só aparentemente obediente ao sistema. Como sabemos, destinado num primeiro momento a cantar as glórias do império, o poema camoniano depara-se contudo com um cenário pouquíssimo favorável à exaltação épica e, por meio dos meandros da linguagem, acaba muito barthesianamente por trapacear a língua, pelo que o poema adquire por diversas vezes uma tonalidade altamente elegíaca, num misto de críticas, queixas, exortações e lamentos. Como pondera Jorge Fernandes da Silveira: “[...] o investimento nos bens de cultura era já tão pouco, quase nenhum, que Camões morreu certo de que o ouro, como metáfora numa poesia de novo engenho e arte, como a sua, estava fadado à miséria" (2008, p.26).

Se a cultura humanista põe em evidencia o valor das letras clássicas e, mais do que isso, se ela, na contramão da Idade Média, evidencia o conceito de autoria como uma questão de suma importância, de modo que, epicamente falando, a imortalização do herói deverá coincidir também ela com a imortalização do artista que se propõe ao canto da sua árdua empresa, Camões, muito pelo contrário, se vê imerso num contexto inóspito à poesia e às artes, por outras palavras, insensível aos valores propalados pelo próprio Humanismo, enfrentando dolorosamente o vazio da interlocução. Neste sentido, não são gratuitas as inúmeras aparições algo narcísicas do poeta ao longo da sua epopeia, a lembrar ao país que o mata lentamente ${ }^{34}$ o seu imenso valor humano, expresso num "honesto estudo", numa "longa experiência" e num grande engenho artístico, coisas raríssimas no seu tempo! Com efeito, é demasiado sintomático, nesta mesma perspectiva de leitura, que Camões tenha entregado por três cantos inteiros a palavra narrativa a Vasco

$33 \quad$ Frase de Ruy Belo acerca da obra de Fernando Pessoa.

$34 \quad$ Verso de Sophia de Mello Breyner Andresen. 
da Gama, o suposto herói coletivo do seu poema, para, ao final do Canto V, frisar "Que ele [Vasco da Gama], nem quem, na estirpe, seu se chama, / Calíope não tem por tão amiga" (V, 99). Criticando a própria coletividade dos heróis que canta, Camões coloca-se de fato como o único herói possível do seu poema. Segundo Helder Macedo, "é o próprio Camões, e não Vasco da Gama, quem encarna a figura do herói da viagem iniciática registada n'Os Lusíadas" (2013, p.49). Afinal, não nos esqueçamos de que é ele quem tem o estudo, a experiência e o talento artístico; assim, no que tange ao contexto da sua epopeia, só ele poderá reintegrar um novo conhecimento à comunidade aí representada porque só ele é um autêntico humanista capaz de manifestar amor aos livros.

Enfim, não houve forte Capitão

Que não fosse também douto e ciente, Da Lácia, Grega ou Bárbara nação, Senão da Portuguesa tão-somente.

Sem vergonha o não digo, que a rezão De algum não ser por versos excelente É não se ver prezado o verso e rima, Porque quem não sabe arte, não na estima.

Por isso, e não por falta de natura, Não há também Virgílios nem Homeros;

Nem haverá, se este costume dura, Pios Eneias nem Aquiles feros.

Mas o pior de tudo é que a ventura Tao ásperos os fez e tão austeros, Tao rudos e de ingenho tão remisso, Que a muitos lhe dá pouco ou nada disso. (V, 95-98)

Subordinando o valor das armas ao valor das letras, Camões reafirma o seu compromisso com o legado ético e estético do Humanismo, assentado, claro está, na recuperação dos grandes modelos clássicos da Antiguidade - e por isso mesmo por ele mais do que justamente citados - mas assentado também, repito, na corrente petrarquista. Com esta afirmação, quero referir-me não exatamente ao tema do erotismo, aspecto em que, como sabemos, Camões se mostra muito mais moderno do que Petrarca, mas sim a um certo exercício filosófico acerca da condição humana delineado no seio da própria poesia, traço comum a ambos os poetas. 
Petrarca foi um grande leitor da produção medieval e mostrou-se sensível o bastante para compreender que no chamado código de amor cortês o objeto feminino nada mais é do que um pretexto para que o amante - entendido etimologicamente como aquele que ama - empreenda um mergulho para dentro de si próprio. Via de introspecção, o amor cortês configura-se como um longo caminho de expiação que vai da visão da Beleza à morte; é, noutros termos, um processo de sondagem da subjetividade masculina. Perscrutando narcisicamente os seus labirintos interiores, o amante cortês questiona-se qual seria a recompensa de louvar, sempre sob o signo de uma coita enlouquecedora, uma dama tão bela e tão virtuosa, dotada de beleza física e de beleza moral. A pergunta que se autoestabelece é no entanto retórica e a resposta que ele mesmo se dá é a de que ganha o seu crescimento espiritual. Ora, é significativo que, num período assinalado pela consciência teocêntrica, o logro das dores de amor corresponda precisamente à ascese da alma. E porque leitor atento da Idade Média, dizia eu, Petrarca, unanimemente considerado o primeiro dos humanistas, acrescentou ao referido processo de sondagem da subjetividade masculina um valor marcadamente humano. Ao louvar Laura, a jovenzinha loura e angelical a quem teria avistado pela primeira vez numa sexta-feira santa, no convento de Santa Clara, em Avignon, Petrarca reafirma, sim, o princípio cortês da escala espiritualizante do amor postulando contudo uma questão jamais imaginável ao homem medieval, que é a da imortalização do artista perante o grande feito da sua obra. Nas palavras de Armindo Trevisan: "Ao contrário de Dante, que ergueu Beatriz à altura do Universo, Petrarca trouxe Laura às dimensões de seu próprio universo. Fez de Laura seu entorno psíquico". E acrescenta: "Crescido no meio das tradições provençais, ao pé do amor cortês, o poeta faz questão de que todos saibam que o seu amor não é vulgar, nem sensual, mas fruto de uma amizade de natureza espiritual" (2014, p.18) Magnífica forma de espiritualidade, tão humanamente capaz de propiciar a ascensão do artista! Desta forma, não é aleatório que o poeta toscano tenha elegido o mito de Apolo e Dafne como arquétipo de um amor que se, por um lado, fisicamente lhe escapa, por outro, espiritualmente o eleva, contemplando-o com a coroa de 
louros, símbolo da imortalidade. Significativamente, não nos olvidemos de que Petrarca gozou do reconhecimento ainda em vida e escolheu para a sua coroação em praça pública as antigas ruínas de Roma, vinculando-se assim à galeria daqueles que se libertaram da lei da morte.

Camões, muito menos ditoso do que Petrarca neste sentido, sofreu a dor de um terrível vazio interlocutório e de um humilhante irreconhecimento que o levou a vir sentenciando a sua própria morte ao longo da sua epopeia:

E ainda, Ninfas minhas, não bastava

Que tamanhas misérias me cercassem,

Senão que aqueles que eu cantando andava

Tal prémio de meus versos me tornassem:

A troco dos descansos que esperava,

Das capelas de louro que me honrassem,

Trabalhos nunca usados me inventaram,

Com que em tão duro estado me deitaram!

Vede, Ninfas, que engenhos de senhores

$\mathrm{O}$ vosso Tejo cria valerosos,

Que assi sabem prezar, com tais favores,

A quem os faz, cantando, gloriosos!

Que exemplos a futuros escritores,

Pera espertar engenhos curiosos,

Pera porem as cousas em memória,

Que merecem ter eterna glória! (VII, 81-82)

Se o tempo humanista português assistiu ao abalo das velhas estruturas medievais mas não chegou a alcançar a idade da razão por meio do amor ao Livro, como quer Jorge Fernandes da Silveira, Camões nunca deixou contudo de resistir àquelas forças externas que punham sob constante ameaça o seu corpo e a sua obra. Daí as suas severas críticas ao valor corruptor do dinheiro e à cobiça geradora de uma gigantesca maquinaria religiosa de sacerdotes sem vocação, que aviltavam as mais belas lições de Cristo, que são a do amor e a da humildade; daí as suas fortes inventivas contra uma justiça injusta, mancomunada com a nobreza, a sobretaxar o povo e a beneficiar apenas os ricos - "Leis em favor do Rei se estabelecem; / As em favor do povo só perecem" (XI, 28) -; daí o seu julgamento frente à postura de superioridade dos mais abastados em rela- 
ção aos mais pobres; daí as suas agudas censuras à exploração do trabalho alheio sem um pagamento que dignificasse "[...] o suor da servil gente" (VII, 86); daí o lugar politicamente libertário assumido na sua poesia no que tange ao uso que cada um confere ao seu corpo e à sua sexualidade e, neste sentido, a lição do poeta não poderia ser mais clara: "[...] Milhor é esprimentá-lo que julgá-lo" (IX, 313). Tudo isso - é preciso dizer - num tempo reprimido pela Inquisição! É pois contra a reificação dos valores humanos que Camões escreve; reificação - repare-se - de que ele próprio também era vítima.

Qualquer semelhança com o nosso tempo não é mera coincidência. Os imperativos humanistas - sujeito racional, alta cultura, dignidade humana - sempre incomodaram as elites porque o crescimento do outro por via do estudo representa para elas a perigosíssima ameaça da perda dos seus privilégios, que durante séculos vêm tomando novas roupagens ao longo da História. Os poetas resistem e ensinam-nos a resistir; os poemas muito pedagogicamente nos ensinam a cair mas também a levantar $^{35}$. Resistamos!

\section{Referências:}

ABBAGNANO, Nicola. Dicionário de Filosofia. Trad. Alfredo Bosi. São Paulo: Mestre Jou, 1962.

ALIGHIERI, Dante. A divina comédia. Edição bilíngue. Trad. e notas de Italo Egenio Mauro. São Paulo: Editora 34, 2017.

ANDRESEN, Sophia de Mello Breyner Andresen. Obra poética. Lisboa: Caminho, (s/d).

BELO, Ruy. Todos os poemas I. Lisboa: Assírio \& Alvim, 2004.

CAMÕES, Luís de. Os Lusíadas. Porto: Porto, 2006.

CHAUÍ, Marilena. "A universidade pública sob nova perspectiva". 2003. Disponível em: http://www.scielo.br/pdf/rbedu/n24/n24a02. pdf. Consulta em: 15 de agosto de 2019.

JORGE, Luiza Neto. Poesia. Lisboa: Assírio \& Alvim, 2010.

LOURENÇO, Eduardo. O labirinto da saudade. Lisboa: Gradiva, 2010.

$\overline{35} \quad$ Parte de um verso de Luiza Neto Jorge. 
MACEDO, Helder. Camões e a viagem iniciática. Rio de Janeiro: Móbile, 2013.

MBEMBE, Achile. "A era do humanismo está terminando". 2017.

Disponível em: https://www.revistaforum.com.br/achille-mbembe-era-do-humanismo-esta-terminando. Consulta em:10 jul. de 2019.

PETRARCA, Francesco. Cancioneiro. Trad. José Clemente Pozenato. Campinas: Ateliê Editorial, 2014.

SILVEIRA, Jorge Fernandes da. O Tejo é um rio controverso: António José Saraiva contra Luís de Camões. Rio de Janeiro: 7 Letras, 2008.

TREVISAN, Armindo. "Petrarca: o poeta que nunca morreu". In:

PETRARCA, Francesco. Cancioneiro. Trad. José Clemente Pozenato. Campinas: Ateliê Editorial, 2014.

TUTIKIAN, Jane. "Qual é o limite?". In: Hora do povo. Disponível em: https://horadopovo.org.br/qual-o-limite. Consulta em:10 jul. de 2019. 